This is an open access article under the CC BY-NC-ND license (https://creativecommons.org/licenses/by-nc-nd/3.0/) Issue III, November 2020

ISSN 2707-9481

ISBN 978-601-323-207-2

https://doi.org/10.31643/2020.031

\section{Xayitali Adinayev}

Institute of General and Inorganic Chemistry of the Academy of Sciences of the Republic of Uzbekistan, Uzbekistan. E-mail: ionxanruz@mail.ru ORCID ID https://orcid.org/0000-0002-9794-4053

\author{
Yodgorjon Safarov \\ Institute of General and Inorganic Chemistry of the \\ Academy of Sciences of the Republic of Uzbekistan, \\ Uzbekistan. E-mail: ionxanruz@mail.ru \\ ORCID ID https://orcid.org/0000-0003-1827-8871
}

\author{
Vitaliy P. Guro \\ Institute of General and Inorganic Chemistry of the Academy of Sciences \\ of the Republic of Uzbekistan, Uzbekistan \\ E-mail: ionxanruz@mail.ru \\ ORCID ID https://orcid.org/0000-0001-5765-0408
}

\title{
Fluidized Bed Pilot Furnace for Modibdenite Concentrate
}

\begin{abstract}
In the Rare Metals Processing Shop (CPRM) at the Almalyk MMC JSC, the technology for processing molybdenite concentrate (MOC) provides for the use of kaolin in the granulation charge for oxidative roasting in a drum furnace. Its composition: 8-10\% kaolin, the rest is molybdenite concentrate (MOC). Kaolin reduces the Mo content in the cinder. Replacing it with an organic binder eliminates this disadvantage (dilution in Mo), but leads to sticking of the granules in the drum furnace. To avoid sticking, it is proposed to replace it with a furnace of a different design. In addition to kaolin as a binder for MOK, ashless, water-soluble polymers are known. Replacing kaolin with them leads to an enrichment in molybdenum of an industrial product - cinder, by 4-5\%. However, for the implementation of such a project, a based selection of the appropriate binder on the local raw material base, modes of its use and replacement of the roasting furnace: drum - with a fluidized (fluidized) bed furnace is required. A binder SK, an alternative to kaolin, and modes of firing granules from a new charge composition with MOC in a fluidized bed furnace have been developed. The design of the fluidized bed furnace has been developed. The introduction of these developments will provide a higher content of Mo in the cinder, better recovery of Mo and Re from it, as well as a lower sulfur content in the cinder, and less time spent on roasting: 1 hour instead of 7 hours in the existing rotary kiln.

Keywords: cinder, molybdenite concentrate, organic binder, kaolin, granulation charge.
\end{abstract}

Cite this article as: Adinayev X., Safarov Y., Guro V. P. (2020). Pilotnaya Pech' Psevdoozhizhennogo Sloya Obzhiga Modibdenitovogo Kontsentrata [Fluidized Bed Pilot Furnace for Modibdenite Concentrate]. Challenges of Science. Issue III, p.: 201-205. (In Russian). https://doi.org/10.31643/2020.031

\section{Хаитали Адинаев}

Институт общей и неорганической химии Академии наук Республики Узбекистан, Узбекистан. Email: ionxanruz@mail.ru ORCID ID https://orcid.org/0000-0002-9794-4053

\section{Едгор Сафаров}

Институт общей и неорганической химии Академии наук Республики Узбекистан, Узбекистан. Email: ionxanruz@mail.ru ORCID ID https://orcid.org/0000-0003-1827-8871 
Виталий П. Гуро

Институт общей и неорганической химии Академии наук

Республики Узбекистан, Узбекистан

Email: ionxanruz@mail.ru

ORCID ID https://orcid.org/0000-0001-5765-0408

\title{
Пилотная Печь Псевдоожиженного Слоя Обжига Модибденитового Концентрата
}

\begin{abstract}
Абстракт. В цехе переработки редких металлов (ЦПРМ) МПЗ АО «Алмалыкский ГМК» технология переработки молибденитового концентрата (МОК) предусматривает использование каолина в составе шихты гранулирования для окислительного обжига в барабанной печи. Ее состав: 8-10\% каолина, остальное молибденитовый концентрат (МОК). Каолин снижает содержание Мо в огарке. Замена его на органическое связующее устраняет этот недостаток (разубоживание по Мо), но приводит к слипанию гранул в барабанной печи. Чтобы уйти от слипания, предложена замена ее на печь иной конструкции. Кроме каолина, как связующего МОК, известны беззольные, водорастворимые полимеры. Замена каолина на них приводит к обогащению по молибдену промышленного продукта - огарка, на 4-5\%. Однако, для реализации такого проекта необходим основанный подбор соответствующего связующего на местной сырьевой базе, режимов его применения и замены печи обжига: барабанной - на печь псевдоожиженного (кипящего) слоя. Разработаны связующее СК, альтернативное каолину, режимы обжига гранул из нового состава шихты с МОК в печи кипящего слоя. Разработана конструкция печи псевдоожиженного слоя. Внедрение этих разработок обеспечит большее содержание Мо в огарке, лучшее извлечение Мо и Re из него, а также меньшее содержание серы в огарке, меньшие затраты времени на обжиг: 1 ч вместо 7 ч в существующей барабанной печи.
\end{abstract}

Ключевые слова: огарок, молибденитовый концентрат, органическое связующее, каолин, шихта гранулирования.

\section{Введение}

Технологией молибдена АО «Апмалыкский ГМК» предусмотрен обжиг молибденитового концентрата (МОК) состава (в \%): влажность 0,42, Mo 38; Re 0,7; Cu 2,5; P 0,009; Sb 0,025; $\mathrm{WO}_{3} 0,05$; $\mathrm{S} 25,2 ; \mathrm{SiO}_{2} 10,8$, с получением огарка промышленного продукта, с содержанием $\mathrm{MoO}_{3}$ не менее $97 \%$. Вследствие близости температур возгорания молибденита $500-510^{\circ} \mathrm{C}$ и начала спекания огарков 580 $590^{\circ} \mathrm{C}$, обжиг ведут при температуре в слое $550-570^{\circ} \mathrm{C}$ (Гуро, В. П., Юсупов, Ф. М., Сафаров, Е.Т., Рахматкариева, Ф. Г., 2016) [1]. На практике (ради повышения возгона семиоксида рения) эту температуру повышают до $580-590{ }^{\circ} \mathrm{C}$ (выше растут потери Мо из-за роста давления паров $\mathrm{MoO}_{3}$ ), тем самым процесс идет в зоне риска налипания. Пока для окислительного обжига МОК применяют барабанную печь, где затруднено поддержание температуры обжига, а перегрев ведет к спеканию материала и неполному окислению сульфидов.

Скорость обжига $\mathrm{MoS}_{2}$ лимитируется диффузией кислорода и отводом диоксида серы из зоны реакции. Печь КС, из всех печей, обеспечивает минимум сопротивления диффузии. Недостатком ее также является низкая производительность. Известны конструкции, пришедшие ей на смену: подовые и печи кипящего слоя. Из-за пыления сульфидных руд при обжиге и потери сырья предварительно их окомковывают В качестве связующего гранулирования традиционно применяют бентонит или каолин, но в последние годы сообщается об органических связующих, взамен глинистых связующих [2-3]. В связи с недостатками вышеуказанной технологии АО «Алмалыкский ГМК»: разубоживании огарка промышленного продукта молибденового по молибдену из-за введения в шихту 8-10\% каолина, закономерен интерес к альтернативной технологии гранулирования и обжига МОК.

Цель работы: разработка пилотной печи КС для испытания новой «безкаолиновой» технологии производства Мо огарка.

Объекты исследования: шихта МОК состава, \%: Мо 36,10; Re 0,055; Си 1,57; S 28, 73 со связующими: каолином Ангренского месторождения, водорастворимыми органическими 
полимерами растительного (СК-К, СК-Д) и синтетического (СК-1) происхождения. Образцы гранул с различными связующими получали в промышленном грануляторе ЦПРМ МПЗ комбината. Обжиг их, согласно (1), осуществляли в муфельной и барабанной печах цеха, а также в пилотной печи кипящего слоя (КС):

$$
\mathrm{MoS}_{2}+3,5 \mathrm{O}_{2}=\mathrm{MoO}_{3}+2 \mathrm{SO}_{2}+\mathrm{Q} \text { кДж }
$$

Скорость обжига таких гранул при температуре выше $600{ }^{\circ} \mathrm{C}$ лимитируется диффузией кислорода и отводом продукта - диоксида серы, из зоны реакции. Для ее увеличения целесообразно уменьшить сопротивление диффузионных стадий за счет измельчения молибденит-содержащиъ фаз и повышения пористости гранул. Рациональным оказался обжиг Мо-сырья в КС-слое, где снижено такое сопротивление, при $580^{\circ} \mathrm{C}$, ответственный за окисление $\mathrm{MOK}$ до $\mathrm{MoO}_{3}$.

Установлено, что в отсутствии перемешивания гранул, в первых двух печах гранулы на основе полимеров СК-К, СК-Д спекаются из-за неполного сгорания органического компонента, а в печи КС - нет. В нем частицы материала находятся в восходящем потоке газа, характеризуемом интенсивным движением (циркуляцией) частиц. В такое состояние зернистый материал переходит при достижении некоторой критической скорости газового потока, определяемой из зависимости между сопротивлением слоя и линейной скоростью газа. Преимущества обжига в КС вытекают из следующих его особенностей:

1) Благодаря хорошему контакту частиц с газом химические реакции в КС протекают быстро;

2) Подвижность слоя, подобная подвижности жидкости, позволяет легко осуществить непрерывную выгрузку, «вытекание» материала из печи через разгрузочную трубу;

3) КС обладает высокими теплопроводностью и коэффициентами теплопередачи. Это позволяет поддерживать во всей массе слоя заданную температуру. Избыточное тепло из слоя легко отводится с помощью холодильников.

4)

1 а - образец гранул Мо-концентрата, сушка на воздухе, при $20{ }^{\circ} \mathrm{C}$, связующее каолин, 9\% в составе шихты гранулирования.

16 - образец гранул Мо-концентрата, обжиг при $600{ }^{\circ} \mathrm{C}$, связующее - каолин, 9\% в составе шихты гранулирования.

1в - образец гранул Мо-концентрата, сушка на воздухе, при $20{ }^{\circ} \mathrm{C}$, связующее полимер СК-К, 2\% в составе шихты гранулирования.

1г - образец гранул Мо-концентрата, обжиг при $600{ }^{\circ} \mathrm{C}$, связующее - полимер СК-К, $2 \%$ в составе шихты гранулирования. 1a

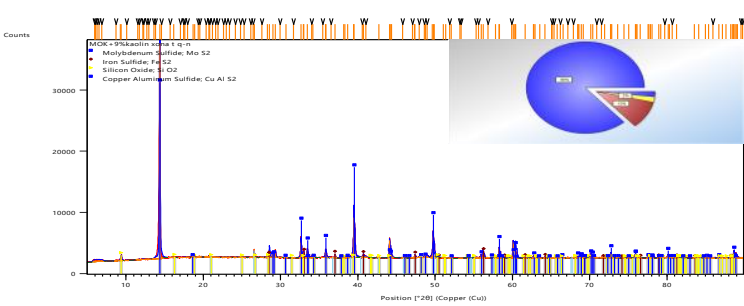

16

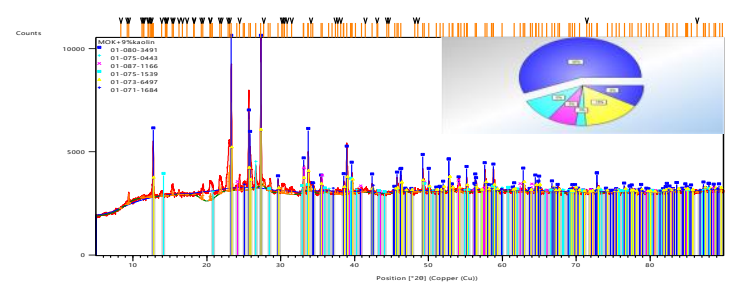

1 в
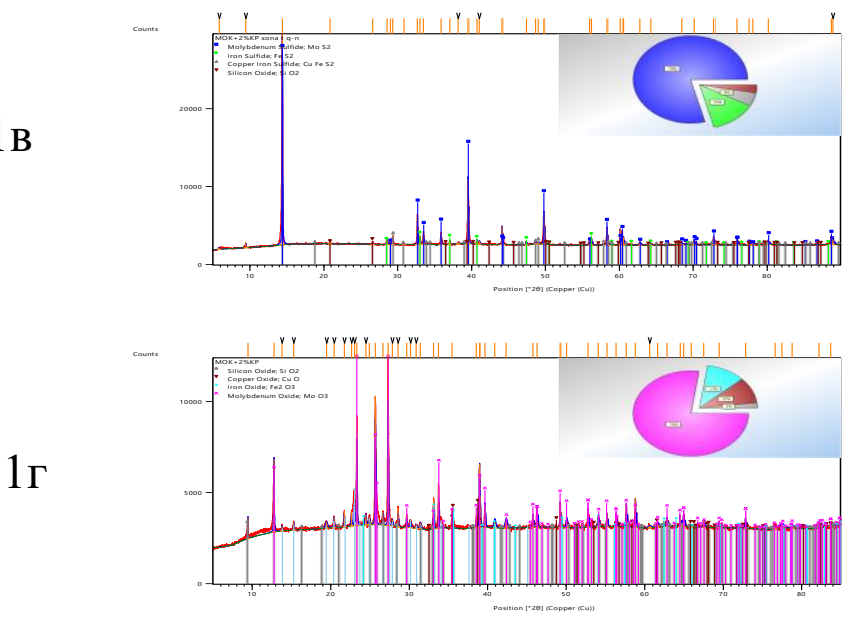

Рис. Рентгеновские дифрактограммы 4-х образцов гранул со связующими разной природы в шихте гранулирования Мо-концентрата, термообработка при 20 и $600{ }^{\circ} \mathrm{C}$ 
Разработана технология производства и применения альтернативного каолину беззольного компонента шихты гранулирования, отличающегося от каолина повышенным, на $5 \%$, содержанием Мо в огарке промышленного продукта молибденового, а также лучшими гидрометаллургическими свойствами его переработки на $\mathrm{Re}, \mathrm{Mo}, \mathrm{Au}, \mathrm{Ag}$. В результате отказа от барабанной печи в пользу печи КС ускоряется выпуск товарной продукции: с 7 ч времени обжига до 1 ч. В результате исследования гранул и огарка, произведенного в печи КС, установлено, что применение в шихте гранулирования Мо-концентрата полимерных связующих имеет преимущество перед применением каолина: необходимое количество полимерного связующего - в 4-10 раз меньше, по сравнению с каолином, при этом обеспечивается большая степень извлечения компонентов Re, Mo из огарка.

Разработана и изготовлена пилотная печь кипящего слоя (КС) (Рузиев, У.Н., Гуро. В.П., Адинаев, Х.Ф., Эрназаров, У. Р., 2020) [4], с габаритами, мм: 2000х2000х1000 и массой 700 кг, частично автоматизированная, с контролем температуры и ее регулированием. В обжиговой зоне создан блок улавливания серного ангидрида и семиоксида рения. Для нее предусмотрен отказ от каолинового связующего и переход к беззольному органическому связующему СК [5] - декстрину, с расходом 1,0-1,5 \% сухого вещества на 100 кг шихты. Качество полученных в печи КС окатышей соответствует техническим условиям TSh 64-23283880-07:2013. Прочность их удовлетворительная. Режимы обжига: в барабанной печи 7 ч, в печи КС - 1 ч. Реализован способ переработки огарка Моконцентрата, полученного обжигом гранулированного Мо-концентрата, сформированного на основе полимерных связующих по Технологической инструкции НПО АО «Алмалыкский ГМК» производства молибденовых соединений ТИ48-4208-5-24-2002. Рекомендован гидрохимический режим переработки огарка (Rasulova, S.N., Guro, V.P., Safarov, E.T., Adinaev, X.F., 2020) [6].

Гранулирование образцов шихты гранулирования МОК разной природы провели в АО «Алмалыкский ГМК», получив контрольную (на основе каолина) и опытную (на основе СК) партии. Время их гранулирования 1 час, полимерное связующее на тарель гранулятора подавался предварительно разбавленный водой в объемном соотношении 1:6, затем гранулы доводились до диаметра 2-4 мм и прочностной кондиции водой и подавались на сушку и обжиг. Режимы обжига в барабанной печи комбината и в печи КС совпадали по температуре $\left(570{ }^{\circ} \mathrm{C}\right)$, но различались по времени: в первом случае - 7 ч, во втором -1 ч. После обжига пробы проанализированы (Perkin-Elmer 3030B и ICP- Aligent 7500 ICP). Поверхность гранул отсканирована (SEM ZEISS EVO MAЮ, CarlZeiss Group). В результате локального рентген-флюоресцентного микроанализа партии 1a следует, что добавка в шихту МОК 8\% каолина обезубоживает материал по Мо, по сравнению с образцами других партий на основе органических связующих. сгоравших при обжиге, образуя пористую структуру, способствующую большей степени окисления молибденита до МоО . Этот вывод подтвержден электронной микроскопией участков поверхности и данными о большей пористости огарка из безкаолиновой шихты, полученными методом сорбции газообразного азота.

Из рентгенограмм поверхности образцов гранул с разной природой связующих (рис.) следует, что применение каолина обедняет их по молибдену. Образцы огарка без каолина (с декстрином) окислены полней (содержание серы ниже). Сравнительный анализ их поверхностей на электронном микроскопе, при перемещении зонда в плоскости над образцами гранул, сформированных без каолина, но с добавкой декстрина, полностью сгорающих в окислительной атмосфере, позволил выявить их большую развитость и наличие пор большего размера, по сравнению с образцами на основе каолина. Образцы, обожженные в печи КС за 0,5-1,0 ч, окислены полностью по молибдениту, до Мо-ангидрида. А каолин-содержащие образцы, обожженные, для сравнения, в барабанной печи, за 7 ч, содержат небольшую долю неокисленного молибденита.

Пилотная печь КС создана для исследований режимов обжига. Она содержит: - реактор в виде вертикальной теплоизолированной трубы с съемным дном-вставкой, имеющий патрубки с фланцами для подачи горячего воздуха снизу и его вывода с обработанным порошком в циклон сверху; фланец-заглушку сверху реактора для обеспечения технического доступа; - устройство загрузки гранул порошка сульфидного концентрата сбоку, закрываемое толстостенным кварцевым стеклом; двухслойную сетчатую поверхность под дном-вставкой реактора для прохождения горячего воздуха через слой гранул пороши концентрата сульфидных руд; - воздухогреющий двухконтурный котел.

Печь КС снабжена скруббером для улавливания возгона семиоксида рения, причем патрубок воздуховода из скруббера возвращается в цикл наддува горелки через регулируемый шибер. Для обеспечения согласования узлов печи, она снабжена электронно-механическим пультом управления с системой измерения температуры в разных частях реактора, изготовленного из нержавеющей стали с крышкой из кварцевого стекла (объем реактора $0,008 \mathrm{~m}^{3}$ ). Осуществляется обжит в ней сульфидного 
сырья на примере МОК, гранулированного с каолином и полимером СК с набором статистики по качеству огарка, согласно TSh 64-23283880-07:2013, ТИ 484208-5-24-2002, технико-экономическим показателям, оптимизации режимов для составления технического задания на проектирование промышленной печи КС.

Для запуска печи первоначально создают в ней кипящий слой из гранул, который разогревают горелкой или подогретым воздухом до зажигания концентрата: $500-510^{\circ} \mathrm{C}$. Затем включают систему питания печи концентратом. Попадая в слой, МОК возгорается, температура повышается и достигает оптимальной температуры обжига $560-570^{\circ} \mathrm{C}$. Вследствие близости температур возгорания МОК в КС $\left(500-510^{\circ} \mathrm{C}\right)$ и начала спекания огарка $\left(580-590^{\circ} \mathrm{C}\right)$, обжиг проводят при относительно низкой температуре в слое, в пределах $\left(560-570^{\circ} \mathrm{C}\right)$. Иначе, при температуре $650-700^{\circ} \mathrm{C}$, растет угроза слипания гранул (огарка) и налипания слоя на стенках печи.

\section{Выводы}

Проведено предварительное сравнительное испытание полимерных связующих взамен каолина при шихтовании Мо-концентрата. Разработан режим обжига гранул на их основе в печи кипящего слоя, взамен барабанной печи. Выявившее преимущество новой технологии (новый состав шихты и замена барабанной речи печью КС) перед существующей. Рекомендовано провести набор статистики результативности обжига МОК в изготовленной пилотной печи КС для подготовки технического задания на проектирование промышленной установки.

Ссылка на данную статью: Адинаев Х., Сафаров Е., Гуро В. П. (2020) Пилотная Печь Псевдоожиженного Слоя Обжига Модибденитового Концентрата. Материалы Международной практической интернет-конференции «Актуальные проблемы науки» [Challenges of Science]. Выпуск III, стр. 201-205. https://doi.org/10.31643/2020.031

\section{Литературы}

[1] Гуро, В. П., Юсупов, Ф. М., Сафаров, Е.Т., Рахматкариева, Ф. Г. (2016). Выбор оптимального связующего для гранулирования молибденитового концентрата. ISSNO 372-2929. Цветные металлы. 2 (68-73). DOI: http://dx.doi.org/10.17580/tsm.2016.02.11.

[2] Патент RU 2353678. Способ окомкования сульфидных молибденитовых концентратов. Палант А.А. (RU), Горбачев М.И. (RU), Морозов И.В.(RU), Москаленко С.А.(RU). МПК С22B1/244 (2006.01). Опубл.: 27.04.2009. Заявка: 2007125956/02, от 10.07.2007. Дата нач. отсч. срока дейс. патента: 10.07.2007.

[3] Патент UZ IAP 06177. Способ окомкования сульфидных молибденитовых концентратов, Приоритет 23.01.2020 по заявке IAP 20170198, авторы: Гуро В.П., Ибрагимова М.А., Сафаров Е.Т. Выдан 31.03.2020. Бюл. № 3.

[4] Рузиев, У.Н., Гуро. В.П., Адинаев, Х.Ф., Эрназаров, У. Р. (2020). Пилотная печь кипящего слоя для обжига сульфидных минералов. Горный вестник Узбекистана. 2 (81), (50-52).

[5] TSh 23766064-05:2017 «Полимеров СК водные растворы. Технические условия». Узстандарт. Ташкент - 2017.

[6] Rasulova, S.N., Guro, V.P., Safarov, E.T., Adinaev, X.F. (2020). Metals recovery from molybdenite concentrate by electrooxidation and leaching. IOP Conf. Series: Materials Science and Engineering 848 (2020) 012076 IOP Publishing doi:10.1088/1757-899X/848/1/012076

\section{References}

[1] Guro, V. P., Yusupov, F. M., Safarov, Ye.T., Rakhmatkariyeva, F. G. (2016). Vybor optimal'nogo svyazuyushchego dlya granulirovaniya molibdenitovogo kontsentrata [Selection of the optimal binder for granulating molybdenite concentrate]. ISSN0 372-2929. Tsvetnyye metally. 2 (68-73). DOI: http://dx.doi.org/10.17580/tsm.2016.02.11. (In Russian).

[2] Patent RU 2353678. Sposob okomkovaniya sul'fidnykh molibdenitovykh kontsentratov [Method for pelletizing molybdenum sulfide concentrates]. Palant A.A. (RU), Gorbachev M.I. (RU), Morozov I.V.(RU), Moskalenko S.A.(RU). MPK C22B1/244 (2006.01). Opubl.: 27.04.2009. Zayavka: 2007125956/02, ot 10.07.2007. Data nach. otsch. sroka deys. patenta: 10.07.2007. (In Russian).

[3] Patent UZ IAP 06177. Sposob okomkovaniya sul'fidnykh molibdenitovykh kontsentratov [Method for pelletizing sulphide molybdenite concentrates], Prioritet 23.01.2020 po zayavke IAP 20170198, avtory: Guro V.P., Ibragimova M.A., Safarov Ye.T. Vydan 31.03.2020. Byul. № 3. (In Russian).

[4] Ruziyev, U.N., Guro. V.P., Adinayev, KH.F., Ernazarov, U. R. (2020). Pilotnaya pech' kipyashchego sloya dlya obzhiga sul'fidnykh mineralov. Gornyy vestnik Uzbekistana [Pilot fluidized bed furnace for sulphide minerals burning. Mining Bulletin of Uzbekistan]. 2 (81), (50-52). (In Russian).

[5] TSh 23766064-05:2017 «Polimerov CK vodnyye rastvory. Tekhnicheskiye usloviya». Uzstandart [CK polymers aqueous solutions. Technical conditions]. Tashkent - 2017. (In Russian).

[6] Rasulova, S.N., Guro, V.P., Safarov, E.T., Adinaev, X.F. (2020). Metals recovery from molybdenite concentrate by electrooxidation and leaching. IOP Conf. Series: Materials Science and Engineering 848 (2020) 012076 IOP Publishing doi:10.1088/1757-899X/848/1/012076 (In English). 